\title{
Differences in the interaction of acetylcholine receptor antibodies with receptor from normal, denervated and myasthenic human muscle
}

\author{
ANN KARI LEFVERT \\ From the Department of Clinical Chemistry, Karolinska Institutet, Karolinska Sjukhuset, Stockholm, Sweden
}

SUMMARY The interaction of acetylcholine receptor antibodies with different kinds of human skeletal muscle receptor was investigated. The reaction of most receptor antibodies was strongest with receptor from a patient with myasthenia gravis and with receptor from denervated muscle. Results obtained with these receptors were well correlated. The binding of most receptor antibodies to receptor from functionally normal muscle was much weaker and also qualitatively different. In a few patients with moderate and severe clinical symptoms the existence of acetylcholine receptor antibodies was revealed only by their reaction with receptor from myasthenic muscle. One patient had a clone of receptor antibodies reacting exclusively with receptor from her own muscle.

The analysis of acetylcholine receptor antibodies has become a valuable tool in the diagnosis of myasthenia gravis and in the monitoring of treatment of this disease. In the individual patient changes in the intensity of the myasthenic symptoms usually coincide with changes in the receptor antibody concentration, but there is no close covariance between the concentration of receptor antibodies and the clinical stage and the disease intensity in a myasthenia gravis population. ${ }^{1}$

The most frequent analytical methods in routine use are based on the binding of receptor antibodies to a complex between a radiolabelled cholinergic ligand, usually a neurotoxin, and a cholinergic receptor preparation, usually from human skeletal muscle. $^{1-3}$ Assays based on inhibition of toxin binding to receptor, ${ }^{4-6}$ complement fixation ${ }^{7}$ and inhibition of receptor binding to Concanavallin- $\mathrm{A}^{5}$ also have been described. Cholinergic receptor preparations from different sources have been used, that is from human skeletal muscle, denervated rat muscle and the electric organ of Torpedo species. The results obtained using different principles of analysis and different kinds of antigen are not concordant. ${ }^{8}$ This may partly reflect antigenic differences between species. ${ }^{9}$ Even within the same

Address for reprint requests: Dr AK Lefvert, Department of Clinical Chemistry, Karolinska Institutet, Huddinge Sjukhus, S-141 86 Huddinge, Sweden.

Received 22 May 1980 and in revised form 9 July 1980 Accepted 4 February 1981 species there is evidence for differences in immunological reactivity between rat receptor from denervated and innervated muscle ${ }^{10}$ and in humans even between receptor from ocular and skeletal muscle. ${ }^{11}$ Further, the receptor antibody is polyclonal and antibodies with different characteristics of binding can be found. ${ }^{6}$ These different antibody populations are likely to have quite different effects on the receptor in situ. Thus, the present analytical methods must be regarded as rather crude tools not capable of distinguishing between different clones of receptor antibodies. In view of the heterogeneity of both the receptor antibodies and the antigens used for their determination, it is important to try to employ more defined test systems both in clinical and in biochemical studies of myasthenia gravis. In this study we have investigated the reaction of the receptor antibodies with different kinds of human skeletal muscle receptor.

\section{Materials and methods}

Preparation and purification of acetylcholine receptor from human skeletal muscle was done as described earlier. ${ }^{1}$ Normal leg muscles were obtained at operation from five patients (age 15 to 23 years) with malignant tumours of the bone. Denervated leg muscles were similarly obtained from four patients (age 57 to 67 years) with diabetes mellitus and advanced neuropathy. Skeletal muscle also was obtained shortly after the death of a patient with 
longstanding myasthenia gravis and bulbar paralysis who died from pneumonia.

Separation of acetylcholine receptor and acetylcholine receptor-IgG complexes from myasthenic muscle The cholinergic receptor and receptor-IgG complexes were extracted from homogenated muscle as described. ${ }^{1}$ The free receptor was separated from receptor complexed with IgG by gel filtration on Sephacryl G300Superfine(Pharmacia Fine Chemicals, Sweden $)$ at room temperature. The column $(5 \times 100$ $\mathrm{cm}$ ) was equilibrated in phosphate buffer, $0.05 \mathrm{~mol} / 1$ with $\mathrm{NaCl}, 0.1 \mathrm{~mol} / \mathrm{l}$ and EDTA, $0.001 \mathrm{~mol} / \mathrm{l}$, pH 7.4, with Triton X-100 $0.5 \%$ and Trasylol to $10^{6}$ Kallikrein inhibitory units/l. Fractions of $5 \mathrm{ml}$ were collected at a rate of $15 \mathrm{ml} / \mathrm{h}$. The content of $\mathrm{IgG}$ in the fractions was measured using an immunoassay. ${ }^{1}$ The sensitivity of this assay is in the order of $0.5 \mathrm{mg} / \mathrm{l}$. The toxin binding capacity of the fractions was measured as described. ${ }^{1}$ The receptor-IgG complex was found in the void volume (fractions $\mathrm{n}$ : 0 99-108) whereas the uncomplexed receptor was mainly found in fractions 115-131. The uncomplexed receptor extract was further concentrated and separated by gel filtration using a column $(25 \times 40$ $\mathrm{cm}$ ) of Sephadex G25 equilibrated in the same buffer. Preparation of ${ }^{125}$ I-labelled $\alpha$-neurotoxin from the venom of Naja naja siamensis, our routine assay for receptor antibodies directed against sites other than the toxin binding site and the assay for receptor antibodies interfering with the toxin binding site were performed as described earlier. ${ }^{16}$ The cholinergic receptor preparations from the normal and from the denervated muscle were diluted to the same concentration (measured as toxin binding capacity) as that of the receptor from the myasthenic muscle. In all assays, the same amount of the three receptors were used $(0 \cdot 1 \mathrm{pmol}$ toxin binding sites/assay). The results of the assay of antibodies interfering with the toxin binding site were expressed in \% inhibition of toxin binding using the effect of normal IgG as zero. The results of the assay for antibodies against sites other than the toxin binding site were expressed in arbitrary units $/ l$, as the amount of receptor antibody in the sample compared with the amount of normal IgG. ${ }^{1}$ Using normal sera in this assay, the amount of CPM precipitated with normal muscle receptor was 150-202, with denervated muscle receptor 173-188, and with myasthenic muscle receptor 161-203. These low background values also in the case of the myasthenic muscle receptor preparation also is a proof that all receptor-IgG complexes had indeed been removed from the preparation.

Separation of receptor antibodies by isoelestric focusing was performed as described earlier. ${ }^{6}$

Patients Sera from 59 patients were tested. Clinical evaluation of these patients had been done at South
Hospital, Stockholm, by Dr G Matell. Ten of these samples were from patients with moderate or severe clinical symptoms of myasthenia gravis and a repeatedly negative routine analysis earlier. Of the other sera five were from patients with ocular myasthenia ( 2 of these samples had been negative in routine assays earlier). Ten samples were from patients in stage IIA, 18 from patients in stage IIB, six from patients in stage III and 10 from patients in stage IV according to the Osserman classification. Statistical analysis was made using non-parametric methods (Wilcoxon test, Kruskal-Wallis test).

\section{Results}

The reactions of receptor antibodies from different patients with different receptor preparations were tested by using the three antigen preparations in the two kinds of analysis for receptor antibodies. The yields of toxin binding sites from the denervated muscle were $3.53 \times 10^{-12}, 5.12 \times 10^{-12}, 2.25 \times 10^{-12}$ and $3.91 \times 10^{-12}$ moles per gram muscle (wet weight). The normal skeletal muscle contained $0.44 \times 10^{-12}$, $0.98 \times 10^{-12}, 1.27 \times 10^{-12}, 0.51 \times 10^{-12}$ and $1.48 \times$ $10^{-12}$ moles per gram muscle. The yield from the myasthenic muscle was $0.12 \times 10^{-12}$ moles toxin binding sites per gram. In this muscle about $45 \%$ of the receptors were found complexed with antibody. In a preliminary study no significant differences were found using denervated muscle receptor from different patients nor using normal muscle receptor from different patients.

Sera from 59 patients were tested with the assay for receptor antibodies directed against sites other than the toxin binding site using the three different antigen preparations. Ten sera were from patients with moderate or severe symptoms and a repeatedly negative routine analysis earlier. The results obtained with the other 49 sera are shown in Fig. 1. Antigen from the myasthenic muscle reacted much better with almost all sera tested than antigen from denervated muscle, while antigen from the normal muscle showed the weakest reaction. There were significant differences between the values obtained with myasthenic muscle and denervated muscle (level of significance 0.005 ), between myasthenic muscle and normal muscle (level of significance $\mathbf{0 . 0 0 1}$ ) as well as between denervated and normal muscle (level of significance 0.01 ). Linear correlation coefficients between results obtained with myasthenic and denervated receptor was 0.83 , between myasthenic and normal receptor 0.30 and between denervated and normal receptor $0 \cdot 20$.

Ten sera which in repeat routine examinations been regarded as negative reacted exclusively with the antigen from the myasthenic muscle. The amount of 


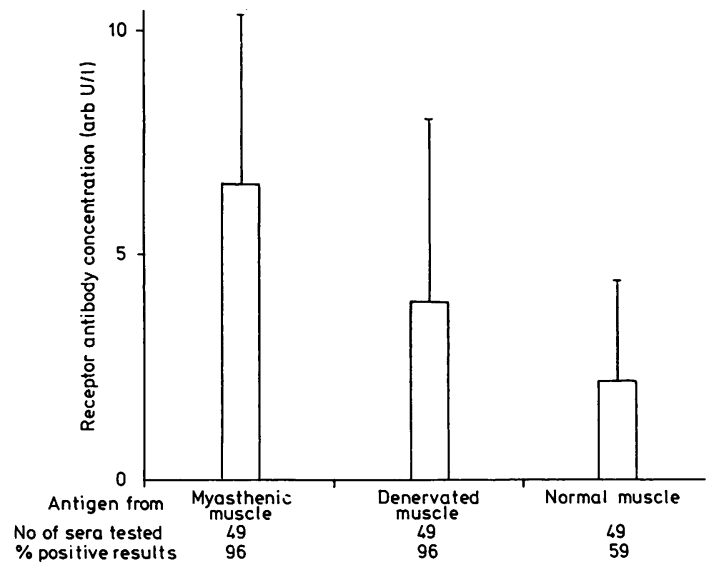

Fig. 1 Receptor antibodies in patients with myasthenia gravis quantitated by their binding to sites other than the toxin binding site on three different receptor preparations. The mean and the standard deviation are shown.

receptor antibodies in these sera was rather low, $\bar{M} 1.92$ arb. units/l, SD 1.95 arb. units/l. Sera from two patients with ocular myasthenia did not react with any of the antigens. Also serum from the patient whose skeletal muscle receptor was used as an antigen was tested. The reaction with the autologous receptor was much stronger than seen with any other serum. The results in arb. units/l using receptor from autologous muscle was $40 \cdot 1$, using denervated muscle $10 \cdot 8$ and using normal muscle $2 \cdot 10$. Separation of these receptor antibodies by quantitative isoelectric focusing (pH 3-10) revealed the existence of a marked peak of receptor antibodies ( $\mathrm{pH} 8 \cdot 88-8.93)$,
$10^{-13}$ moles of toxin binding sites bound per $10 \mu \mathrm{g}$ of IgG, reacting only with the autologous receptor but not with receptor from denervated or normal muscle. Receptor antibodies reacting with all three antigen preparations were present in several fractions (pH 5-10) up to a concentration of $2 \times 10^{-14}$ moles of toxin binding sites bound per $10 \mu \mathrm{g}$ of IgG (Fig. 2). Isoelectric focusing was used to separate the receptor antibodies from five other patients. In no case was it possible to demonstrate a clone of antibodies binding exclusively to the receptor from the myasthenic muscle or to one of the other receptor preparations.

Inhibition of toxin binding to receptor was studied using the different receptor preparations. Serum from the myasthenic patient inhibited maximally $60 \%$ of the toxin binding to receptor from her own muscle, and 40 and $6 \%$, respectively, of the binding to denervated and normal muscle receptor. The fraction of this receptor antibody with pI 8.88-9.93 inhibited maximally $25 \%$ of toxin binding to the myasthenic muscle only. Sera from 12 other patients were tested on their ability to inhibit toxin binding to the different antigen preparations. All these sera had high concentrations of antibodies reacting with sites other than the toxin binding site. Also in this modification of assay the receptor prepared from the myasthenic muscle showed the best reaction with the majority of the sera (Fig. 3). The difference between values obtained with myasthenic receptor and denervated receptor was not significant. There were significant differences between myasthenic and normal receptor (level of significance 0.001) and between denervated and normal receptor (level of significance $0 \cdot 05$ ).

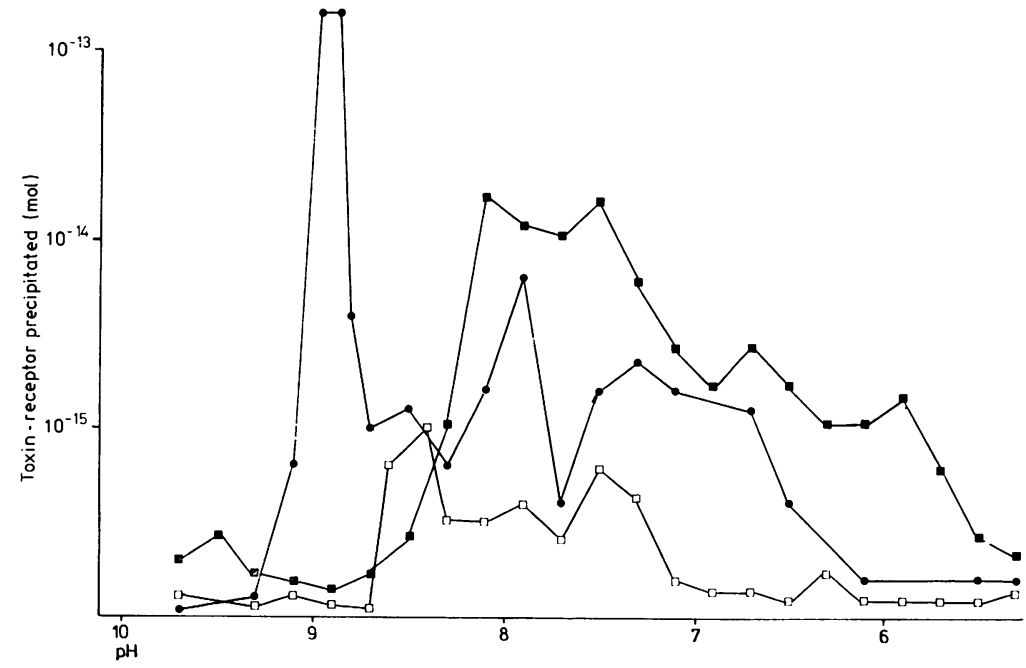

Fig. 2 Separation of receptor antibodies from a patient with myasthenia gravis by isoelectric focusing. Fractions of $10 \mu \mathrm{g} \mathrm{IgG}$ were analysed for binding to different kinds of skeletal muscle receptor.

$\square-\square$ Receptor from normal muscle

$\square$ Receptor from denervated muscle

- Receptor from myasthenic, autologous muscle 


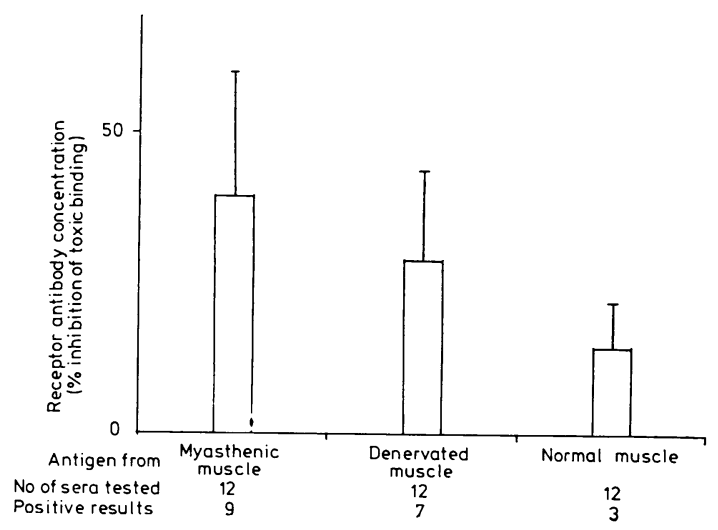

Fig. 3 Receptor antibodies in patients with myasthenia gravis quantitated by their interference with toxin binding to three different receptor preparations. The mean and the standard deviation are shown.

Of the ten sera who reacted exclusively with the myasthenic muscle in the assay of receptor antibodies against sites other than the toxin binding site, four showed a weak inhibition of toxin binding to myasthenic muscle (15-22\% inhibition) but not to the other muscle receptor preparations.

\section{Discussion}

There exists considerable differences in the reactions of receptor antibodies with skeletal muscle receptor from normal, denervated and myasthenic muscle. The receptors from our myasthenic muscle and those from denervated muscle seem to be immunologically similar in their interaction with the antibodies, although most antibodies reacted stronger with receptor from the myasthenic muscle. On the other hand, the reaction of the antibodies with receptor from normal muscle was much weaker and also qualitatively different. Of course the denervated muscle contained both normal and extrajunctional receptors. This should have been the case also with the muscle from the myasthenic patient. However, the differences in antibody reaction with these three receptor preparations are large enough to suggest, that most of the receptor antibodies in myasthenia gravis are directed against determinants on extrajunctional receptors and on degenerated receptors and that their reaction with functionally normal receptors is limited.

The existence of a clone of receptor antibodies reacting exclusively with the autologous receptor and unique for the patient, is interesting and merits further study. A patient with longstanding myasthenia gravis and much structural damage to the synapse is likely to develop antibodies against previously hidden or inaccessible determinants. Some of these antigenic sites seem to be unique for the disease myasthenia gravis, as the antibody in 10 of our patients with rather severe clinical disease reacted only with the antigen from a myasthenic muscle. Our findings also suggest that some of the antibody clones might be unique for each patient. Thus, the absolute level of receptor antibodies as measured in routine assays is of rather limited value and in many cases does not reflect the true concentration of antibodies against the acetylcholine receptor.

\section{References}

${ }^{1}$ Lefvert AK, Bergström 'K, Matell G, Osterman PO, Pirskanen R. Determination of acetylcholine receptor antibody in myasthenia gravis: Clinical usefulness and pathogenetic implications.J Neurol Neurosurg Psychiatry $1978 ; 41: 394-403$.

${ }^{2}$ Lindstrom $\mathbf{J}$. An assay for antibodies to human acetylcholine receptor in serum from patient with myasthenia gravis. Clin Immunol Immunopathol 1977;7:36-43.

${ }^{3}$ Monnier VM, Fulpius BW. A radioimmunoassay for the quantitative evaluation of anti-human acetylcholine receptor antibodies in myasthenia gravis. Clin Exp Immunol 1977;29:16-22.

${ }^{4}$ Almon KR, Andrew CG, Appel SH. Serum globulin in myasthenia gravis: Inhibition of $\alpha$-bungarotoxin binding to acetylcholine receptors. Science 1974;186:55-7.

5 Mittag T, Kornfeld P, Tormay A, Woo C. Detection of anti-acetylcholine receptor factors in serum and thymus from patients with myasthenia gravis. $N$ Engl $J$ Med 1976;294:691-4.

${ }^{6}$ Lefvert AK, Bergström K. Acetylcholine receptor antibodies in myasthenia gravis: Purification and characterization. Scand J Immunol 1978;8:525-33.

7 Aharonov A, Abramsky O, Tarrab-Hazdai R, Fuchs S. Humoral antibodies to acetylcholine receptor in patients with myasthenia gravis. Lancet 1975;2:340-2.

${ }^{8}$ Lefvert AK. Acetylcholine receptor antibodies in myasthenia gravis. Thesis. Stockholm 1978.

"Dau PC, Yano CS, Ettinger SJ. Antibody to acetylcholine receptor in canine and human myasthenia gravis: differential crossreactivity with human and rabbit receptor. Neurology (Minneap) 1979;29:1065-8.

${ }^{10} \mathrm{Almon}$ RR, Appel SH. Interaction of myasthenic serum globulin with the acetylcholine receptor. Biochim Biophys Acta $1975 ; 393: 67-77$.

1 Vincent A, Newsom-Davis J. $\alpha$-bungarotoxin and antiacetylcholine receptor antibody binding to the human acetylcholine receptor. In: Ceccarelli B, Clementi F, ed. Advances in cytopharmacology, vol. 3. New York: Raven Press, 1979. 